\title{
FAKTOR-FAKTOR YANG MEMPENGARUHI PRODUKTIVITAS TENAGA KERJA PADA USAHA TERNAK AYAM RAS PEDAGING DI KABUPATEN PASURUAN
}

\section{NOVI ITSNA HIDAYATI}

Jurusan Agribisnis, Fakultas Pertanian Universitas Yudharta Pasuruan

\begin{abstract}
ABSTRAK
Usaha peternakan ayam ras pedaging merupakan salah satu usaha yang dapat menghasilkan perputaran modal yang sangat cepat serta harga daging yang relatif murah dan mudah terjangkau oleh semua lapisan masyarakat. Sumber daya manusia merupakan salah satu faktor yang penting dalam keberhasilan dan keberlanjutan usaha ayam ras pedaging. Kualitas dari sumber daya manusia yang mengelola usaha ternak ayam ras pedaging bisa dilihat dari faktor-faktor seperti motivasi, disiplin kerja, keterampilan kerja dan skala usaha pada usaha peternakan ayam ras pedaging dalam rangka mengetahui pengaruh produktivitas tenaga kerja ayam ras pedaging. Tujuan dari penelitian ini adalah: 1) mengetahui faktor motivasi kerja, disiplin kerja, keterampilan kerja dan skala usaha berpengaruh terhadap produktivitas tenaga kerja pada usaha ternak ayam ras pedaging; 2) mengetahui faktor-faktor yang berpengaruh dominan terhadap produktivitas tenaga kerja pada usaha ternak ternak ayam ras pedaging.

Hasil penelitian menunjukkan bahwa faktor motivasi kerja, disiplin kerja, keterampilan kerja dan skala usaha berpengaruh signifikan terhadap produktivitas tenaga kerja pada usaha ternak ayam ras pedaging. Dalam penelitian ini digunakan analisis regresi linier berganda dengan hasil sebagai berikut: $\mathrm{Y}=$ $118,84+14,05 X_{1}+14,09 X_{2}+13,35 X_{3}+12,25 X_{4}$. Dari hasil analisi tersebut menunjukkan bahwa disiplin kerja memberikan pengaruh hubungan dan kontribusi yang signifikan terhadap produktivitas tenaga kerja. Pengaruh yang paling dominan terdapat pada disiplin kerja yaitu 14,09 yang dapat diinterpretasikan bahwa bila disiplin kerja meningkat $1 \%$ maka akan meningkat pula motivasikerja karyawan sebesar $14,09 \%$.
\end{abstract}

\section{PENDAHULUAN}

Peternakan merupakan salah satu subsektor agribisnis yang mempunyai prospek yang sangat bagus bila dikembangkan secara optimal. Kemajuan dan perkembangan subsektor peternakan akan membawa dampak positif dalam meningkatkan kesejahteraan petani. 
Pembangunan subsektor peternakan merupakan bagian dari sektor pertanian negara secara umum dan bagian dari pembangunan nasional secara keseluruhan. Pembangunan subsektor peternakan bertujuan untuk meningkatkan produksi peternakan dengan prioritas untuk pemenuhan kebutuhan pangan dan gizi serta meningkatkan pendapatan peternak.

Agribisnis peternakan merupakan segala aktivitas bisnis yang terkait dengan kegiatan budidaya ternak, industri hulu, industri hilir, dan lembaga-lembaga pendukung. Agribisnis tersebut merupakan salah satu bidang yang sangat penting bagi hajat hidup masyarakat dan memiliki potensi dijadikan sebagai penggerak utama ekonomi nasional. Usaha peternakan bahkan mampu meningkatkan ekonomi pedesaan dan sekaligus meningkatkan pendapatan masyarakat desa. Banyak faktor yang dapat mempengaruhi produktivitas tenaga kerja dalam bekerja.

Pertumbuhan populasi ternak nasional ayam ras pedaging dari tahun 2009 sampai 2013 cenderung mengalami kenaikan. Kondisi ini membuktikan bahwa peluang dan potensi peternakan ayam ras pedaging masih sangat prospek untuk dikembangkan. Populasi ayam ras pedaging hampir disemua daerah mengalami kenaikan, hal ini berpengaruh terhadap produksi daging yang dihasilkan. Ayam ras pedaging merupakan salah satu jenis unggas yang cukup berkembang pesat di Jawa Timur (Tabel 1).

Tabel 1 Populasi Ayam Ras Pedaging Menurut Beberapa Propinsi 2009 - 2013 (ekor)

\begin{tabular}{|c|l|r|r|r|r|r|}
\hline No & \multicolumn{1}{|c|}{ Propinsi } & \multicolumn{1}{c|}{$\mathbf{2 0 0 9}$} & \multicolumn{1}{c|}{$\mathbf{2 0 1 0}$} & \multicolumn{1}{c|}{$\mathbf{2 0 1 1}$} & \multicolumn{1}{|c|}{$\mathbf{2 0 1 2}$} & \multicolumn{1}{c|}{$\mathbf{2 0 1 3}$} \\
\hline 1 & Jawa barat & 455.258 .895 & 497.814 .154 & 583.263 .441 & 610.436 .303 & 680.452 .807 \\
\hline 2 & Jawa Tengah & 58.350 .965 & 64.332 .799 & 66.239 .700 & 76.906 .291 & 80.082 .520 \\
\hline 3 & D.I.Yogyakarta & 5.276 .897 & 5.435 .521 & 5.770 .832 & 5.814 .935 & 6.113 .547 \\
\hline 4 & Jawa Timur & 147.006 .266 & 56.993 .631 & 149.552 .720 & 155.945 .927 & 159.844 .575 \\
\hline 5 & Banten & 80.023 .212 & 41.146 .851 & 52.272 .333 & 54.151 .644 & 59.932 .454 \\
\hline 6 & Bali & 5.263 .645 & 5.404 .657 & 6.206 .641 & 5.872 .311 & 5.642 .550 \\
\hline & Indonesia & $\mathbf{1 . 0 2 6 . 3 7 8 . 5 8 0}$ & $\mathbf{9 8 6 . 8 7 1 . 7 1 2}$ & $\mathbf{1 . 1 7 7 . 9 9 0 . 8 6 9}$ & $\mathbf{1 . 2 4 4 . 4 0 2 . 0 1 6}$ & $\mathbf{1 . 3 5 5 . 2 8 8 . 4 1 9}$ \\
\hline
\end{tabular}

Sumber: Direktorat Jenderal Peternakan 2013

Populasi ayam ras pedaging di Jawa Timur sekitar $11,8 \%$ dari total keseluruhan populasi ayam ras pedaging di Indonesia. Usaha ternak ayam ras pedaging merupakan usaha yang dapat menghasilkan perputaran modal yang cepat dan harga yang murah sehingga mudah dijangkau oleh semua lapisan masyarakat. Kabupaten Pasuruan merupakan salah satu kabupaten di Jawa Timur yang memiliki populasi ayam ras 
pedaging cukup besar sehingga mampu memenuhi $70 \%$ kebutuhan daging di Jawa Timur dan secara nasional mampu memenuhi 30\% kebutuhan daging Nasional.
Tahun 2010 jumlah populasi ayam ras ras pedaging Kabupaten Pasuruan mencapai 31.225.776 ekor dengan jumlah produksi daging sebesar 33.367 ton (Tabel 2).

Tabel 2 Populasi Ternak Unggas menurut Beberapa Kabupaten (ekor)

\begin{tabular}{|r|l|r|r|r|}
\hline No & \multicolumn{1}{|c|}{ Kabupaten / Kota } & $\begin{array}{l}\text { Ayam buras } \\
\text { (Domestik hen) }\end{array}$ & $\begin{array}{l}\text { Ayam Pedaging } \\
\text { (Broiler Hen) }\end{array}$ & $\begin{array}{l}\text { Ayam Petelur } \\
\text { (Laying Hen) }\end{array}$ \\
\hline 1 & Jombang & 1.409 .221 & 19.423 .784 & 1.088 .730 \\
\hline 2 & Nganjuk & 1.182 .869 & 2.395 .456 & 1.052 .603 \\
\hline 3 & Madiun & 1.016 .528 & 589.124 & 156.828 \\
\hline 4 & Tulungagung & 2.161 .823 & 1.495 .494 & 3.432 .410 \\
\hline 5 & Blitar & 2.341 .098 & 21.873 .600 & 13.900 .400 \\
\hline 6 & Kediri & 1.187 .814 & 8.339 .818 & 7.163 .057 \\
\hline 7 & Malang & 1.807 .318 & 13.346 .528 & 2.666 .662 \\
\hline 8 & Pasuruan & 1.839 .632 & 31.225 .776 & 110.108 \\
\hline 9 & Jember & 1.605 .080 & 4.234 .131 & 782.035 \\
\hline 10 & Banyuwangi & 1.290 .229 & 1.483 .054 & 599.000 \\
\hline & Jawa Timur & $\mathbf{2 4 . 0 0 6 . 8 1 4}$ & $\mathbf{5 6 . 9 9 3 . 6 3 1}$ & $\mathbf{3 7 . 0 3 5 . 2 5 1}$ \\
\hline
\end{tabular}

Sumber : Dinas peternakan Jawa Timur 2011

Kecamatan Kejayan merupakan salah satu daerah penghasil ayam ras pedaging terbesar di Kabupaten Pasuruan. Kecamatan Kejayan memiliki potensi tinggi untuk pengembangan usaha ternak ayam ras pedaging. Mayoritas masyarakat memiliki ternak ayam ras pedaging baik sebagai kerjaan utama maupun kerjaan sampingan.

\section{METODE PENELITIAN}

Responden dalam penelitian ini adalah peternak ayam ras pedaging yang ada di Kecamatan Sugio Kabupaten Lamongan Propinsi Jawa Timur. Pelaksanaan penelitian dari bulan Februari sampai Mei 2014. Jumlah peternak responden yang diambil dalam penelitian ini sebanyak 75 peternak yang diambil secara teknik (stratified random sampling) dengan skala usaha 3000 - 6000 ekor per produksi. Skala usaha adalah jumlah kepemilikan ternak ayam pedaging (jumlah ayam yang dipelihara) oleh seorang peternak persiklus produksi pemeliharaan.

Data dikumpulkan melalui empat cara yaitu: (1) wawancara langsung, menggunakan kuesioner terstruktur yang telah disiapkan, (2) Wawancara mendalam menggunakan daftar pertanyaan terbuka sebagai pedoman wawancara, (3) Observasi untuk melihat kegiatan maupun hasil kegiatan usaha ayam ras pedaging yang 
telah biasa dilakukan oleh peternak (responden) dan (4) dokumentasi.

Analisis data yang digunakan untuk mengetahui faktor yang mempengaruhi produktivitas tenaga kerja pada usaha peternakan ayam ras pedaging digunakan rumus regresi linier berganda, dimana :

$$
\begin{aligned}
\mathbf{Y}= & \mathbf{a}+\mathbf{b}_{1} \mathbf{X}_{1}+\mathbf{b}_{2} \mathbf{X}_{\mathbf{2}}+\mathbf{b}_{3} \mathbf{X}_{\mathbf{3}}+\mathbf{b}_{\mathbf{4}} \mathbf{X}_{\mathbf{4}}+\mathbf{E} \\
\mathrm{Y}= & \text { Produktivitas tenaga kerja (jumlah } \\
& \text { ternak yang dipelihara } / \text { HKSP) } \\
\mathrm{a}= & \text { Konstanta } \\
\mathrm{X}_{1}= & \text { Motivasi kerja (scoring) } \\
\mathrm{X}_{2}= & \text { Disiplin kerja (scoring) } \\
\mathrm{X}_{3}= & \text { Keterampilan kerja (scoring) } \\
\mathrm{X}_{4}= & \text { Skala usaha (ekor) } \\
\mathrm{E}= & \text { Standar error }
\end{aligned}
$$

Untuk mengetahui pengaruh masingmasing variabel independen terhadap variabel dependen secara simultan (bersamasama) dilakukan uji F, sedangkan untuk mengetahui pengaruh variabel independen terhadap variabel dependen secara parsial (sendiri-sendiri) dilakukan uji t dengan dasar keputusan sebagai berikut :

a. Jika $F_{\text {hit }}$ lebih besar dari $F_{\text {tab }}$ berarti variabel independen $(\mathrm{X})$ secara simultan memberikan pengaruh signifikan terhadap variabel dependen (Y).

b. Jika $t_{\text {hit }}$ lebih besar dari $t_{\text {tab }}$ berarti variabel independen $(\mathrm{X})$ secara parsial berpengaruh signifikan terhadap variabel dependen (Y).

Dalam menginterpretasikan bagaimana penilaian tenaga kerja terhadap indikator faktor-faktor yang mempengaruhi produktivitas tenaga kerja maka dibutuhkan suatu rentang kelas. Untuk mengetahui rentang kelas (range) dengan rumus sebagai berikut:

Range $=\frac{(\text { jumlah skor tertinggi }- \text { jumlah skor terendah })}{\text { banyaknya skala pengukuran }}$

Penilaian masing-masing indikator faktor-faktor yang mempengaruhi produktivitas tenaga kerja pada usaha peternakan ayam ras pedaging di Kecamatan Kejayan Kabupaten Pasuruan yaitu dilakukan dengan:

Nilai tertinggi : 5 x $50 \times 4=1000$

Nilai terendah : 1 × $50 \times 4=200$

Range $=\frac{(1000-200)}{5}=\frac{800}{5}=160$

Dari hasil tersebut dirumuskan sebagai berikut :

$\begin{array}{ll}\text { Sangat baik } & =840-1000 \\ \text { Baik } & =680-840 \\ \text { Cukup } & =520-680 \\ \text { Kurang baik } & =360-520 \\ \text { Sangat tidak baik } & =200-360\end{array}$

Instrumen dalam penelitian ini digunakan untuk mengukur nilai variabel yang akan diteliti. Adapun instrumen penelitian faktor-faktor yang mempengaruhi produktivitas tenaga kerja peternak ayam ras pedaging di Kecamatan Kejayan Kabupaten Pasuruan dapat dilihat pada tabel 3 di bawah ini. 
Tabel 3. Instrumen Penelitian Faktor-faktor yang Mempengaruhi Produktivitas Tenaga Kerja pada Usaha Ternak Ayam Ras Pedaging

\begin{tabular}{|l|l|l|l|l|}
\hline No & Variabel & Sub variabel & Indikator Pengukuran & Instrumen \\
\hline 1 & Variabel dependen $(\mathrm{Y})$ & & $\begin{array}{l}\text { Jumlah ternak yang ditangani } \\
\text { / curahan tenaga kerja } \\
\text { (ekor/HKSP) }\end{array}$ & Kuisioner \\
\hline 2 & Variabel Independen $(\mathrm{X})$ & $\begin{array}{l}\text { - Motivasi } \\
- \text { Harapan } \\
\text { Motivasi kerja }\left(\mathrm{X}_{1}\right)\end{array}$ & $\begin{array}{l}\text { - Alasan ekonomis } \\
- \text { Perasaan tenang waktu } \\
\text { bekerja } \\
\text { Jaminan hari tua } \\
\text { Pendapatan yang layak }\end{array}$ & Kuisioner \\
\hline & Disiplin kerja $\left(\mathrm{X}_{2}\right)$ & & $\begin{array}{l}\text { Tingkat ketepatan waktu } \\
\text { bekerja }\end{array}$ & Kuisioner \\
\hline 3 & Keterampilan kerja $\left(\mathrm{X}_{3}\right)$ & & $\begin{array}{l}\text { - Banyaknya pelatihan yang } \\
\text { diikuti } \\
\text { Tingkat pemahaman materi } \\
\text { yang berhubungan dengan } \\
\text { pekerjaan }\end{array}$ & Kuisioner \\
\hline
\end{tabular}

\section{HASIL DAN PEMBAHASAN}

Variabel dalam penelitian ini me;iputi: variabel dependen (produktivitas tenaga kerja) dan variabel independen (motivasi kerja, disiplin kerja, keterampilan kerja dan skala usaha).

\section{Produktivitas tenaga kerja}

Produktivitas tenaga kerja adalah perbandingan antara jumlah hasil ternak ayam ras pedaging sekali panen dengan curahan tenaga kerja selama pemeliharaan.
Produktivitas tenaga kerja ini menunjukkan tingkat keberhasilan peternak ayam ras pedaging di Kecamatan Sugio Kabupaten Lamongan dalam usaha meningkatkan pendapatan / kesejahteraan bagi peternak. Untuk mengetahui produktivitas tenaga kerja ayam ras pedaging di Kecamatan Kejayan Kabupaten Pasuruan Berdasarkan skala usaha dapat dilihat pada tabel 4 di bawah ini. 
Tabel 4 Rata-rata Produktivitas Tenaga Kerja pada Skala Usaha Ternak Ayam Ras Pedaging

\begin{tabular}{|l|c|c|c|}
\hline No & $\begin{array}{c}\text { Produktivitas tenaga kerja / } \\
\text { hari }\end{array}$ & $\begin{array}{c}\text { Jumlah responden } \\
\text { (orang) }\end{array}$ & Persentase (\%) \\
\hline 1 & $105-179,7$ & 30 & 40 \\
\hline 2 & $91-98$ & 12 & 16 \\
\hline 3 & $83,1-88,7$ & 15 & 20 \\
\hline 4 & $72,3-81,2$ & 8 & 11 \\
\hline 5 & $53,1-68,4$ & 10 & 13 \\
\hline \multicolumn{2}{|l}{ Jumlah } & 75 & 100 \\
\hline
\end{tabular}

Sumber: diolah dari data primer

Dari tabel di atas menunjukkan bahwa produktivitas tenaga kerja yang paling banyak adalah $105 \quad-\quad 179,7$ dengan persentase $40 \%$. Sedangkan produktivitas yang paling rendah adalah $72,3-81,2$ dengan persentase $11 \%$. Tinggi rendahnya pencapaian produktivitas kerja ini tergantung dari penggunaan jam kerja yang efisien yang dilakukan oleh pekerja di Kecamatan Kejayan Kabupaten Lamongan.

Tabel 5 Motivasi Kerja pada Usaha Ternak Ayam Ras Pedaging di Kecamatan Kejayan Kabupaten Pasuruan

\begin{tabular}{|c|c|c|c|c|c|c|}
\hline No & Indikator & Kategori & $\begin{array}{l}\text { Nilai } \\
\text { (skor) }\end{array}$ & $\begin{array}{c}\text { Frekuensi } \\
\text { (orang) }\end{array}$ & $\begin{array}{c}\text { Persentas } \\
\text { e }(\%)\end{array}$ & Total skor \\
\hline \multirow{5}{*}{1} & \multirow{5}{*}{$\begin{array}{c}\text { Alasan } \\
\text { ekonomis }\end{array}$} & Sangat mendorong & 5 & 67 & 90 & 225 \\
\hline & & Mendorong & 4 & 6 & 8 & 16 \\
\hline & & Cukup mendorong & 3 & 2 & 2 & 3 \\
\hline & & Tidak mendorong & 2 & 0 & 0 & 0 \\
\hline & & $\begin{array}{ll}\begin{array}{l}\text { Sangat } \\
\text { mendorong }\end{array} & \text { tidak }\end{array}$ & 1 & 0 & 0 & 0 \\
\hline \multicolumn{4}{|c|}{ Jumlah } & 75 & 100 & 244 \\
\hline 2 & Perasaan & Sangat tenang & 5 & 66 & 88 & 220 \\
\hline
\end{tabular}




\begin{tabular}{|c|c|c|c|c|c|c|}
\hline No & Indikator & Kategori & $\begin{array}{l}\text { Nilai } \\
\text { (skor) }\end{array}$ & $\begin{array}{l}\text { Frekuensi } \\
\text { (orang) }\end{array}$ & $\begin{array}{c}\text { Persentas } \\
\text { e }(\%)\end{array}$ & Total skor \\
\hline & \multirow{4}{*}{$\begin{array}{l}\text { tenang } \\
\text { waktu } \\
\text { bekerja }\end{array}$} & Tenang & 4 & 7 & 10 & 20 \\
\hline & & Cukup tenang & 3 & 2 & 2 & 3 \\
\hline & & Tidak tenang & 2 & 0 & 0 & 0 \\
\hline & & Sangat tidak tenang & 1 & 0 & 0 & 0 \\
\hline \multicolumn{4}{|c|}{ Jumlah } & 75 & 100 & 243 \\
\hline \multirow{5}{*}{3} & \multirow{5}{*}{$\begin{array}{l}\text { Jaminan } \\
\text { hari tua }\end{array}$} & Sangat menjamin & 5 & 66 & 88 & 220 \\
\hline & & Menjamin & 4 & 5 & 7 & 16 \\
\hline & & Cukup menjamin & 3 & 4 & 5 & 6 \\
\hline & & Tidak menjamin & 2 & 0 & 0 & 0 \\
\hline & & Sangat tidak menjamin & 1 & 0 & 0 & 0 \\
\hline \multicolumn{4}{|c|}{ Jumlah } & 75 & 100 & 236 \\
\hline \multirow{5}{*}{4} & \multirow{5}{*}{$\begin{array}{c}\text { Pendapata } \\
\text { n yang } \\
\text { layak }\end{array}$} & Sangat puas & 5 & 70 & 94 & 235 \\
\hline & & Puas & 4 & 5 & 6 & 12 \\
\hline & & Cukup puas & 3 & 0 & 0 & 0 \\
\hline & & Tidak puas & 2 & 0 & 0 & 0 \\
\hline & & Sangat tidak puas & 1 & 0 & 0 & 0 \\
\hline \multicolumn{4}{|c|}{ Jumlah } & 75 & 100 & 247 \\
\hline \multicolumn{6}{|c|}{ Total } & 970 \\
\hline
\end{tabular}

Sumber : diolah dari data primer

Dari tabel 5 dapat diketahui bahwa motivasi yang dimiliki oleh pekerja pada pemeliharaan ayam pedaging dapat mempengaruhi jumlah skala usaha yang dimilikinya sehingga pendapatan pekerja akan naik. Hal ini sesuai dengan pendapatnya Sedarmayanti (2001) yang menyatakan bahwa tidak ada motivasi jika tidak dirasakan adanya kebutuhan dan kepuasan serta ketidak seimbangan. Rangsangan terhadap hal tersebut akan menumbuhkan motivasi dan mendorong untuk mencapai tujuan pemenuhan kebutuhan atau pencapaian keseimbangan.
Baiknya motivasi tenaga kerja pada usaha ternak ayam ras pedaging di kecamatan Kejayan kabupaten Pasuruan berdasarkan jumlah responden terlihat dari jumlah populasi keseluruhan ayam ras pedaging yang cukup tinggi yaitu 385.000 ekor. Hal ini menunjukkan bahwa usaha ternak ayam ras pedaging mempunyai prospek yang menguntungkan untuk dikembangkan.

\section{Disiplin kerja}

Disiplin kerja merupakan suatu kerajinan, ketaatan, dan keuletan dalam melaksanakan tugas sehingga keberadaan 
disiplin kerja merupakan unsur utama dalam pencapaian kuantitas hasil panen. Disiplin kerja yang dimiliki oleh para pekerja pemeliharaan ayam ras pedaging di kecamatan Kejayan Kabupaten Pasuruan dalam menjalankan tanggung jawabnya memberikan dampak terhadap produktivitas kerja. Diskripsi data disiplin kerja pasa usaha ternak ayam ras pedaging di kecamatan Kejayan Kabupaten Pasuruan dapat dilihat pada tabel 6 di bawah ini.

Tabel 6 Disiplin Kerja pada Usaha Ternak Ayam Ras Pedaging di Kecamatan Kejayan Kabupaten Pasuruan.

\begin{tabular}{|c|l|c|c|c|c|}
\hline \multirow{2}{*}{ No } & \multicolumn{1}{|c|}{ Kategori } & Nilai (skor) & $\begin{array}{c}\text { Frekuensi } \\
\text { (Orang) }\end{array}$ & $\begin{array}{c}\text { Persentase } \\
(\mathbf{\%})\end{array}$ & Total Skor \\
\hline \multirow{3}{*}{1} & 5 & 69 & 92 & 230 \\
\cline { 2 - 6 } & Sangat tepat waktu & 4 & 6 & 8 & 16 \\
\cline { 2 - 6 } & Tepat waktu & 3 & 0 & 0 & 0 \\
\cline { 2 - 6 } & Cukup tepat waktu & 2 & 0 & 0 & 0 \\
\cline { 2 - 6 } & Tidak tepat waktu & 1 & 0 & 0 & 0 \\
\cline { 2 - 6 } Sangat tidak tepat & 1 & $\mathbf{7 5}$ & $\mathbf{1 0 0}$ & $\mathbf{2 4 6}$ \\
\hline \multicolumn{2}{|c|}{ Jumlah } & & & \\
\hline
\end{tabular}

Sumber : diolah dari data primer

Dari tabel di atas terlihat bahwa kedisplinan kerja sangat baik dalam usaha ternak ayam ras pedaging sehingga dapat berpengaruh terhadap produksi daging. Tingginya disiplin kerja peternak ayam ras pedaging di Kecamatan Kejayan Kabupaten Pasuruan terlihat dari ketepatan waktu dalam melaksanakan tugasnya yaitu memberi makan, minum, dan vaksinasi yang sering dilakukan.

\section{Keterampilan kerja}

Keterapilan kerja merupakan suatu penguasaan teknik kerja pada pemeliharaan ayam ras pedaging yang diperoleh melalui pelatihan baik secara formal maupun nonformal. Hasil analisa menunjukkan bahwa keterampilan tenaga kerja pada usaha ternak ayam ras pedaging di Kecamatan Kejayan Kabupaten pasuruan sangat baik sehingga dapat meningkatkan produktivitas kerjanya. Diskripsi data keterampilan kerja dapat dilihat pada tabel 7 di bawah ini. 
Tabel 7 Keterampilan kerja pada Usaha Ternak Ayam Ras Pedaging di Kecamatan kejayan Kabupaten Pasuruan

\begin{tabular}{|c|c|c|c|c|c|c|}
\hline No & Indikator & Kategori & $\begin{array}{l}\text { Nilai } \\
\text { (skor) }\end{array}$ & $\begin{array}{c}\begin{array}{c}\text { Frekuensi } \\
\text { (orang) }\end{array} \\
\end{array}$ & $\begin{array}{c}\text { Persentase } \\
(\%)\end{array}$ & Total skor \\
\hline \multirow{5}{*}{1} & \multirow{5}{*}{ Pelatihan } & $>5$ kali & 5 & 66 & 88 & 220 \\
\hline & & 5 kali & 4 & 3 & 4 & 8 \\
\hline & & 4 kali & 3 & 3 & 4 & 6 \\
\hline & & 3 kali & 2 & 2 & 2 & 2 \\
\hline & & $<3$ kali & 1 & 2 & 2 & 1 \\
\hline \multicolumn{4}{|c|}{ Jumlah } & 75 & 100 & 237 \\
\hline \multirow{5}{*}{2} & \multirow{5}{*}{$\begin{array}{c}\text { Tingkat } \\
\text { pemahaman }\end{array}$} & Sangat paham & 5 & 67 & 90 & 225 \\
\hline & & paham & 4 & 7 & 10 & 20 \\
\hline & & Cukup paham & 3 & 1 & 2 & 3 \\
\hline & & Tidak paham & 2 & 0 & 0 & 0 \\
\hline & & $\begin{array}{ll}\text { Sangat tidak } \\
\text { paham }\end{array}$ & 1 & 0 & 0 & 0 \\
\hline \multicolumn{4}{|c|}{ Jumlah } & 75 & 100 & 245 \\
\hline \multicolumn{6}{|c|}{ Total } & 482 \\
\hline
\end{tabular}

Sumber : di olah dari data primer

Tingginya tingkat keterampilan yang dimiliki oleh pekerja pada usaha ternak ayam ras pedaging di Kecamatan Kejayan Kabupaten Pasuruan terlihat dari pola pemberian pakan dan minum yang sesuai secara teknis. Hal ini disebabkan pada umumnya para pekerja sering mengikuti pelatihan yang diselenggarakan oleh instansi teknis (Dinas Peternakan setempat).

\section{Skala usaha}

Skala usaha ternak ayam ras pedaging di Kecamatan Kejayan Kabupaten Pasuruan terdiri dari 3 jenis skala usaha yaitu 3000, 4000, dan 6000 ekor. Adapun skala usaha ayam ras pedaging yang ditangani oleh responden dapat dilihat pada tabel 8 di bawah ini.

Tabel 8 Skala Usaha pada Usaha Ternak Ayam Ras Pedaging di Kecamatan Kejayan Kabupaten Pasuruan

\begin{tabular}{|c|c|c|c|}
\hline No & Skala Usaha (ekor) & Responden (orang) & Persenatase (\%) \\
\hline 1 & 3000 & 38 & 50 \\
\hline 2 & 4000 & 30 & 40 \\
\hline 3 & 6000 & 7 & 10 \\
\hline \multicolumn{2}{|r|}{ Jumlah } & 75 & 100 \\
\hline
\end{tabular}

Sumber : data primer 
Pada tabel dapat dijelaskan bahwa skala usaha 3000 ekor merupakan skala usaha yang paling banyak diminati oleh responden yaitu sebesar $50 \%$, sedangkan skala usaha yang paling besar yaitu 6000 ekor hanya diminati oleh responden sebesar $10 \%$. Jumlah ayam ras pedaging yang diusahakan sangat bergantung pada kemampuan peternak dalam menyediakan kandang beserta fasilitasnya.

Hal ini sesuai dengan pendapat Sirajuddin (2004) bahwa produktivitas tenaga kerja juga dipengaruhi oleh skala usaha. Produktivitas kerja adalah kemampuan produk (output) yang dihasilkan setiap satuan tenaga kerja (HKP) yang digunakan. Produktivitas kerja akan bertambah dengan semakin meningkatnya skala usaha.

Hasil analisis regresi linier berganda menunjukka bahwa:

$Y=118,84+14,05 X_{1}+14,09 X_{2}+13,35$

$\mathrm{X}_{3}+12,25 \mathrm{X}_{4}$.

Dari persamaan diatas dapat dilihat bahwa variabel disiplin kerja $\left(\mathrm{X}_{2}\right)$ mempunyai pengaruh yang paling besar terhadap produktivitas tenaga kerja pada usaha ternak ayam pedaging di Kecamatan Kejayan Kabupaten Pasuruan.

\section{Hipotesis Uji F dan Uji t}

Hasil analisis uji $\mathrm{F}$ menunjukkan bahwa $\mathrm{F}_{\text {hit }} \geq \mathrm{F}_{\text {tab }}$ yaitu $18,42 \geq 2,58$ yang berarti signifikan. Hal ini berarti variabel motivasi kerja, disiplin kerja, keterampilan kerja dan skala usaha berpengaruh signifikan terhadap produktivitas tenaga kerja pada usaha ternak ayam pedaging di Kecamatan Kejayan. Sedangkan hasil uji $t$ secara parsial menunjukkan bahwa $t_{\text {hit }} \geq t$ tab yang artinya variabel motivasi kerja, disiplin kerja, keterampilan kerja dan skala usaha berpengaruh positif dan signifikan terhadap produktivitas tenaga kerja pada usaha ternak ayam pedaging di Kecamatan Kejayan.

\section{KESIMPULAN DAN SARAN}

\section{Kesimpulan}

1. Dari variabel bebas bisa dilihat yaitu: motivasi memiliki pengaruh terhadap produktivitas tenaga kerja pada usaha ternak ayam pedaging karena berhubungan dengan semangat dan keberlangsungan seorang pekerja dalam menjalankan pekerjaannya. Sedangkan disiplin kerja berpengaruh dalam ketepatan waktu yang mana untuk pencapaian hasil ternak dari kondisi ayam itu sendiri maupun daging yang dihasilkan supaya sesuai dengan target yang diinginkan. Untuk keterampilan kerja berpengaruh dalam keaktifan dan kreatifitas seseorang dalam bekerja sehingga mampu menangani ternak ayam dengan baik, dan skala usaha juga 
berpengaruh terhadap produktivitas tenaga kerja. Semakin besar skala usaha (jumlah ternak) yang diusahakan maka semakin besar pula nilai produktivitas tenaga kerja yang dihasilkan.

2. Dari hasil analisa regresi linier berganda di peroleh bahwa yang berpengaruh dominan terhadap produktivitas tenaga kerja pada usaha ternak ayam pedaging adalah disiplin kerja karena kedisiplinan para pekerja tersebut dapat memproduksi daging sesuai dengan apa yang ditargetkan. Semua itu berkat kerja keras para pekerja dalam pemberian pakan, minum dan membersihkan kandang setiap harinya.

\section{Saran}

1. Peternak ayam pedaging di Kecamatan Kejayan Kabupaten Pasuruan dalam meningkatkan produktivitas tenaga kerja perlu ada kesinambungan dari motivasi kerja, disiplin kerja, keterampilan kerja dan skala usaha agar terus ditingkatkan untuk keberlangsungan dari usaha ayam pedaging.

2. Dari hasil penelitian ini perhitungan produktivitas kerja hanya dilakukan pada perhitungan jam kerja saja selama satu kali siklus produksi, maka disarankan pada peneliti selanjutnya untuk menghitung produktivitas kerja yang dilakukan selama satu periode waktu atau selama setahun sehingga bisa melihat variasi atau perubahan penggunaan curahan tenaga kerja.

\section{DAFTAR PUSTAKA}

Cayati, M. Ufrani. 1997. Analisis Pendapatan Usahatani Ayam Broiler di Kecamatan Rendang Kabupaten Karangasem (Skripsi). Denpasar: Fakultas Peternakan Universitas Udayana.

Hafsah, M. J. 2000. Kemitraan Usaha, Konsep dan Strategi.Cetakan kedua. Jakarta:Penebar Swadaya.

Husnan, Suad dan Suwarsono. 1992. Studi Kelayakan Proyek. Unit Penerbit dan Percetakan AMP YKPN. Yogyakarta.

Ibrahim, H.M. Yacob. 2003. Studi Kelayakan Bisnis. Jakarta: PT.Rineka Cipta.

Rahardja, Prathama dan Mandala Manurung. 2001. Teori Ekonomi Mikro, Suatu Pengantar. Jakarta: LPFE - UI.

Rasyaf, M. 1987. Beternak Ayam Pedaging. Jakarta: Penebar Swadaya.

Saragih. 2001. Agribisnis Paradigma Baru Pembangunan Ekonomi Berbasis pertanian. Kumpulan Pemikiran, Diedit oleh R. Pambudy, T. Sipayung, J.R.Saragih, Burhanudin dan Frans D.M.Dabukke. Terbitan Kedua. Yayasan Mulia Persada Indonesia dan PT. Surveyor Indonesia Bekerjasama dengan Pusat Studi Pembangunan IPB dan USESE Foundation, Bogor. 
Suparta, N. 2001. Perilaku Agribisnis dan Kebutuhan Peternak Ayam Ras Pedaging. Disertasi. Bogor: Institut Pertanian Bogor.

Suparta, N. 2005. Pendekatan Holistik
Membangun Agribisnis. Cetakan Pertama. Denpasar: CV.Bali Media Adhikarsa.

Sutojo, S. 1991. Studi Kelayakan Teori dan Praktek. Jakarta: PT.Pressink. 